\title{
Sugestões para a reforma do código do ar
}

\section{José Dalmo Fairbanks Belfort de Mattos}

o Snr. Ministro da Aeronáutica, buscando atualizar a legislação vigente, cometeu à Comissão de Estudos Relativos à Navegação Aérea Internacional (G. E. R. N. A. 1.) - "o estudo e a revisão geral do Código Brasileiro do Ar e disposições legais subsequentes". Cabe-lhe mais, pelo Aviso 75, de 5/8/47, apresentar "um ante-projeto de lei sôbre a materia, de forma a ser firmada uma legislação codificada e atualizada, relativa a tráfego e ao transporte aéreo e assuntos correlatos".

o Snr. Brigadeiro do Ar, Hugo da Cunha Machado, Presidente da Comissäło, houve por bem dirigir-nos o oficio 11/48, aos 23 de janeiro deste ano, solicitando nossa contribuição.

Dai o presente trabalho, que lhe foi remetido aos 9 de abril, sob registro AR. 28.950, e que se publica abaixo, na integra.

O Código Brasileiro do Ar, em suas linhas gerais, segue diretrizes fecundas, e que muito têm contribuido para ò desenvolvimento do tráfego aeronáutico no País. Notadamente a parte relativa ao "Direito Publico Aéreo", assente na doutrina da soberania do Estado sôbre o espaço aéreo, creação de aeroportos aduaneiros, de corredores de passagem, etc. - assegura ao máximo a segurança nacional. E, ao mesmo tempo, reduz, quanto possivel, os óbices à locomoção aérea.

Apresentaremos, a seguir, algumas sugestões para a reforma de certos artigos, atendendo ao apelo que nos foi feito pela C. E. R. N. A. I., e, ao mesmo tempo, às orientacões atuais do Direito Público. 


\title{
A NOÇÃo DE TERRITóRIO
}

\begin{abstract}
ARTIGO 5.
TEXTO ATUAL

Consideram-se em território do Estado subjacente, quaisquer aeronaves militares ali $\mathrm{em}$ vôo ou em pouso.

\section{TEXTO PROPOSTO}

Consideram-se em território do Estado subjacente, quaisquer aeronaves NÃO militares, ali em vôo ou em pouso.

$\S$ único - Excetuam-se, porém:

1.0) Os casos admitidos pelo Direito Internacional Comum, ou pelas Convenções e Tratados ratificados pelo Brasil;

$2.0)$ as aeronaves estrangeiras não militares, às quais o governo federal conceder os beneficios de extra-territoriedade, por meio de um Decreto especial.
\end{abstract}

\section{JUSTIFICAÇĀO}

A presente redação do art. $5 .^{\circ}$ deve ter provindo de um lapso tipográfico. Já o demonstrou claramente o Prof. Dr. Hugo Srmmas, em seu "Código Brasileiro do Ar Anotado", pág. 40.

0 texto origina-se, com efeito, de uma emenda do Prof. Dr. Haroldo Valadão, ao ante-projeto da 8." Comissão.

E esta emenda diz exatamente o contrário do texto or $x$ em vigor.

Não podia deixar de fazê-lo.

As aeronaves militares estrangeiras, quer sobrevôem nosso território, quer nele pousem, são consideradas sempre como território do País, cuja "cocarde" exibem.

E' a lição consagrada pelas Convenções Internacionais. 
o CóDIGo BUSTAMANTE, aprovado na 6. Conferência Pan-Americana, adotado por 17 Repúblicas deste Continente, ratificado e promulgado entre nós, em 1929, declara, em seu art. 300, não serem aplicáveis as leis do País, "aos delitos cometidos em águas territoriais, ou no ar territorial, a bordo de navios ou aeronaves de guerra"

E Alcorta, o grande jurista argentino, comenta esse inciso de uma forma irreplicavel:

"Las naves o aeronaves extranjeras de guerra SON PORCIONES FLOTANTES DEL ESTADO a que pertencem, esto es, PARTES FLOTANTES DE SU TERRITORIO" (Proyecto de Código de Derecho Internacional Privado", in "Revista de la Facultad de Derecho y Ciencias Sociales" de Buenos-Ayres, tomo VI. , pag. 680).

E, tanto escapam à soberania do Estado sobrevoado, que se admite a possibilidade das aeronaves militares estrangeiras concederem ASILO a criminosos políticos (Vide "Convenção Pan-Americana sobre Direito de Asilo", assinada em Havana, aos 20/2/28, art. 2. ; Convenção de Montevidéo, de $26 / 12 / 33$, art. $1 .^{\circ}$, assinada por ocasião da $7 .^{*}$ Conferência Pan-Americana).

O novo Tratado de Montevidéo, firmado a 4/8/39 declara expressamente:

"El asilo solamente puede conceder-se en las Embajadas, los buques de guerra, campamentos, O AERONAVES MILITARES".

Todos esses convênios foram ratificados pelo Itamaratí.

A doutrina internacional, unânime, consagra idêntico princípio. Veja-se, no mesmo sentido: Mario Giuliano "La navigazione aerea nel diritto internazionale generale"; Bonfils-Fauchille - "Traité de Droit International $\mathrm{Pu}$ - 
blic", vol. 2. ${ }^{\circ}$; Clovis BeviltQua - "Direito Público Internacional", vol. $1 .^{\circ}, \S 63$, etc.

Verifica-se, pois, que, em sua redação atual, o art. $5 .^{\circ}$ não se coaduna com o direito internacional, adotado entre as nações cultas.

E não é só. Menos ainda se ajusta ao art. $4 .^{\circ}, \S$ único, do próprio Código Brasileiro do Ar.

Com efeito, em face dêsse último artigo:

"Consideram-se território do Estado de sua nacionalidade as aeronaves militares, ONDE QUER QUE SE ENCONTREM".

Como afirmar, logo em seguida, que elas possam considerar-se em território do Estado subjacente?

E' evidente, pois, como sugerem alguns autores, que o verdadeiro texto, óra vigente, de acôrdo aliás, com a emenda Haroldo Valadão, deveria mencionar:

\section{“. . aeronaves NÃO MILITARES"}

Sugerimos, porém, um aditamento ao texto assim emendado. Ou melhor: - restaurado em seu primitivo teor.

Casos existem em que se poderia atribuir extraterritoriedade a aeronaves estrangeiras, mesmo não militares.

Tais prerrogativas derivam:

a) Do Direito Internacional Comum (geralmente consuetudinário). Exs.: aeronaves governamentais não militares, a cujo bordo viajem Chefes de Estado estrangeiros;

b) De Convenções bi ou multilaterais, que venham a ser assinadas pelo Itamarati. Exs.: os aviões, eventualmente pertencentes à Organização das Nações Unidas, e a seus Departamentos, aos quais se pretenda atribuir regalias especiais.

$\mathrm{Ou}$ as aeronaves estrangeiras, auxiliares dos corpos expedicionários internacionais, aos quais o País conceder 
livre sobrevôo, nos termos do art. $43 \mathrm{n} .{ }^{\circ} 1$ da "CARTA DAS NAÇôES UNIDAS", e art. $5^{\circ}$ n. $^{\circ} \mathrm{V}$ da Constituição de 1946.

c) De favores concedidos pelo governo federal para cada caso concreto (aviões de abastecimento de forças de algum Estado americano, ao qual o País conceda posição de não-beligerante, nos termos dos Acôrdos da II. ${ }^{a}$ Conferência de Chanceleres; aeronaves transportando missões científicas estrangeiras de grande relevância, etc.).

Todas essas hipóteses encontram-se contempladas no texto por nós apresentado.

\section{ARTIGO $6 .^{\circ}, \S$ ÚNICO}

\section{TEXTO ATUAL}

Se tais atos se originem de uma aeronave, considerada território brasileiro, atingindo as suas conseqüências território estrangeiro, serão cumulativamente do dominio das leis brasileiras e leis estrangeiras.

\section{TEXTO PROPOSTO}

$\S 1 .^{\circ}$ - Se tais atos se originarem de uma aeronave, considerada território brasileiro, atingindo as suas conseqüuencias território estrangeiro, serão cumulativamente do dominio das leis brasileiras e das leis estrangeiras, no concernente ao processo e punição criminal dos responsaveis;

$\S 2 .^{\circ}-$ A responsabilidade civil será, entretanto, apurada pela Justiça local, de acordo com os tratados vigentes entre os dois Paises, ou, à sua falta, segundo a lei interna, vigorante no local da prática do ato;

$\S 3 .^{\circ}$ - Caso, porém, a União, ou o Estado Federado sejam citados como Réus ou assistentes, em ditos processos civeis, será competente para julgá-los a Justiça Brasileira, que aplicará os Tratados vigentes entre ambos os Paises, 
ou, à sua falta, o direito brasileiro.

Não será aplicavel essa competência privativa, caso a intervenção da União ou do Governo Estadual, nos litigios, seja feita de maneira expontânea;

$\S 4 .^{\circ}$ - A aceitação, pelo Governo Estadual, da jurisdição estrangeira somente será possivel, mediante autorização e assistência da União, através de sua Procuradoria Judicial.

\section{JUSTIFICAÇÃO}

$O$ inciso supra, fruto de uma emenda aos arts. 145/146 do ante-projeto, consagra, atualmente, a comnetência cumulativa, não apenas no campo criminal, mas tambem no de direito civil (ressarcimento de danos causados pelas aeronaves, ou por objetos tombados de seu bordo, ou alijados, etc.).

Ora, tal competência justifica-se em matéria penal, dada a gravidade dos delitos, sua repercussão internacional, e o dever de cooperação dos Estados na repressão da criminalidade.

O princípio de competências concorrentes, em casos tais, foi reconhecido pela "CORTE PERMANENTE DE JUSTIÇA INTERNACIONAL", no "Caso Lotus" (abalroamento marítimo). E isto, não apenas quanto ao direito substantivo aplicavel, mas tambem quanto à jurisdição, às normas do processo.

"La Cour", diz a sentença, "croit devoir souligner le fait qu'il n'apparaît pas que les États interessés se soient opposés aux porsuites pénales relatives à des cas d'abordage devant les Tribunaux d'un pays autre que celui du pavillon, ou qu'ils aient 
avancé des protestations" (ap. Jean Haemmerlé "Iaa Coutûme en Droit des Gens, d'après la Jurisprudence de la C. P. J. I.", pag. 46).

Isso, aliás, em casos culposos ocorridos em mar alto, onde o choque das soberanias provém apenas da diferença de pavilhões entre os navios em litígio.

Em tais casos, pois, a jurisdição e competência decorrem da iniciativa processual de qualquer dos dois Estados. Interessados ambos no esclarecimento da verdade, e na punição dos culpados.

Bem diverso é, porém, o quadro no que concerne às QUESTõES CIVEIS. Não existe, á, o dever moral de cooperação punitiva. Não existe, tambem, sempre a mesma semelhança de lineamentos, entre as legislações eventuaimente aplicaveis. Semelhança esta que se nota nas leis penais dos povos cultos.

Alguns Estados não admitiriam a responsabilidade civil das aeronaves públicas, por danos eventualmente causados à superfície do solo. Adotam outros as normas da Convenção de Roma. Outros, enfim, não limitam a responsabilidade a um máximo legal.

Verifica-se, pois, que a existência ou não da responsabilidade civil, seu montante eventual, as medidas assecuratórias cabiveis para a garantia do crédito decorrente $e x$ delictu, variarão conforme o Estado que tomar a iniciativa do processo. Ou permitir que o mesmo se instaure perante seus Tribunais.

A.o A., na espécie, ficará a faculdade de escolher, nãı apenas o Fôro e o Juizo, mas a lei a aplicar. Será êle, em sintese, que, pela escolha da Justiça e da Lei aplicavel, dirá, a priori, se o R. é ou não responsavel. E a medida de sua responsabilidade.

Ainda mais: nos termos do art. $4 .^{\circ}$ do Código do Ar, somente se consideram "território do Estado de sua nacio- 
nalidade", quando em sobrevôo de território estrangeiro, as aeronaves militares.

Logo, na vigência dos atuais textos, somente aeronaves militares brasileiras poderão beneficiar-se com o disposto neste $\S$ único.

Em processos civeis de indenização, a União aparecerả como litisconsorte passivo, na qualidade de empregadora, e nos expressos termos da Constituição Federal. E os aeronautas serão seus prepostos, caso sejam membros da F.A.B.

Caso, porém, eventualmente pertençam às forças aéreas estaduais (como a esquadrilha aeronáutica da Força Pública Paulista, anterior a 1930), será o Estado Federado o co-responsavel pela indenização.

Tal co-responsabilidade, pois, no regimen de competência cumulativa, poderia submeter a União ou os Estados Federados a verem-se na posição de RR., ou de assistentes ante um Tribunal Estrangeiro.

Ora, se é bem verdade (como frisa Clovis BevilaQua), que

“não se opõe à soberania do Estado que êle se submeta à jurisdição de um Tribunal de outro, em matéria de ordem privada" (Direito Público Internacional, vol. $1 .^{\circ}$, pág. 79 ),

é bem de vêr que tal posição não se presume. E que o Tribunal Estrangeiro somente será competente:

$\left.1 .^{\circ}\right)$ caso o Estado o aceite expressamente;

$\left.2 .^{\circ}\right)$ caso o aceite, de maneira tácita, apresentando pedido reconvencional;

3..$^{\circ}$ caso não oponha exceção declinatoria fori;

$\left.4 .^{\circ}\right)$ ou quando a ação intentada verse acerca de imoveis pertencentes ao Estado, sitos em território sujeito à jurisdição do Estado processante.

Caso contrário, somente poderá ser acionado no Rio de Janeiro, de acordo com a lei nacional, e o fôro privativo. 
Ao passo que os Estados-membros responderão em Juizo igualmente privativo, em suas Capitais, e de conformidade com suas normas de organização judiciária.

Não poderão responder em fôro estrangeiro, salvo autorização expressa da União, a quem compete representar o País no Exterior. A autorização prévia compete ao Presidente da República. Uma vez concedida, deverá o Estado ser assistido no pleito, pela União, através de seu orgão competente.

O texto por nós proposto atende a todas essas possibilidades: competências concurrentes em matéria criminal; competência da Justiça local para os processos civeis; fôro privativo para a União e os Estados Federados, salvo comparecimento expontâneo perante Tribunal Estrangeiro; autorização prévia e assistência da União, caso o Estado $\mathrm{Fe}$ derado deseje aceitar a jurisdição de Côrtes Judiciais de Paises Estrangeiros.

Quanto aos demais artigos da Introdução ao Código do Ar, magistralmente redigidos pelo Dr. Haroldo Valadão e seus companheiros da 8." Comissão, parece-nos que devem ser mantidos. Estão absolutamente de acordo com o Direito Internacional (Público e Privado) e atendem cuidadosamente às necessidades de nosso tráfego aéreo.

\section{REGISTRO DAS AERONAVES ADQUIRIDAS COM RESERVA DE DOMfNIO.}

Julgamos que será interessante o novo Código do Ar apresentar um regulamento sucinto da compra de aeronaves a prestações, de maneira a permitir-lhes o registro competente.

Essa regulamentação está, de certa maneira, prevista no atual artigo 27: 
“Qualquer ato jurídico ou fato, que possa alterar a situação jurídica de uma aeronave, será transcrito no Registro Aeronáutico Brasileiro, e averbado, no certificado de matricula".

Sabemos que o extinto CONSELHO NACIONAL DE AERONÁUTICA proferiu a respeito brilhante parecer, no processo $23.733 / 40$, determinando que, em tais casos

"se faça a matrícula no nome do comprador, com anotação de reserva de domínio, em favor do vendedor".

Cumpre notar, porém:

a) que o Conselho Nacional de Aeronáutica era, áquela época, orgão meramente consultivo;

b) Que tal orgão não mais existe;

c) Que o citado parecer foi homologado pelo Snr. Ministro da Viação, então competente, quando, agora, tal atribuição caberia ao da Aeronáutica.

Vê-se, pois, que tal parecer, em extremo interessante e fecundo, constitue, hoje, méra opinião doutrinária, que (parece) não vem sendo seguida pela Diretoria de Aeronáutica Civil.

Deve-se ainda levar em consideração que, de conformidade com o art. 22 do Código do $\mathrm{Ar}$, não poderão ser inscritas no Registro, as aeronaves pertencentes a estrangeiros, mas que estejam sendo adquiridas a prestações por nacionais.

Falha grave: - pois, nessas condições, seu registro somente será possivel após totalmente pagas. Nesse meio tempo, o aparelho continuará a exibir os sinais distintivos de sua matrícula, em terra estranha, e somente poderá sobrevoar o País como aeronave estrangeira (art. 20). Tal exigência traduzir-se-á, em $90 \%$ dos casos, na paralização do aparelho, enquanto durar sua aquisição. 
Os prejuizos que daí decorrem para a aviação mercantil são enormes, e redundam numa diminuição da eficiência do nosso tráfego aeronáutico.

o razoavel, parece-nos, será conceder-lhe inscrição $e$ matrícula condicionais, como aeronave nacional, uma vez que esteja na posse e uso exclusivo de nacionais.

Esse registro dará baixa em caso de caducidade do contrato e retomada da coisa, pelo proprietário estrangeiro.

Nessa hipótese, deverá êle ser cancelado, a pedido do adquirente, ou ex-officio, mediante comunicação das autoridades aeronáuticas.

\section{A AERONáutica Não COMERCIAL.}

Legislação elaborada com a participação direta de representantes da aeronáutica mercantil, o Código do Ar deu o melhor de suas atenções às "linhas regulares de navegação aérea".

Faltam-lhe dispositivos orgânicos, que regulamentem a aviação de turismo. Já o assinalávamos em nossa tese “Direito Público Aéreo", publicada em 1938.

Já, àquele tempo, Wladmir MANDL havia dito, na dupla investidura de doutor em Direito e piloto brevetado:

"En ce qui concerne le tourisme aérien, s'il lui faut un statut exceptionnel, c'est parce qu'il se trouve dans des conditions dont tous les pays se sont efforcés de l'encourager afin d'intéresser le public aux choses de l'air, soit par égard au commerce, soit pour soutenir la défense nationale aérienne" (LES ÉTATS DE LA PETITE ENTENTE ET L'UNIFICATION DU DROIT AÉRIEN".

Pouco depois, o antigo Conselho Nacional da Aeronáutica declarava, em sessão realizada a $2 / 3 / 39$, que o Código do Ar 
“é omisso quanto à aviação civil ou desportiva".

$\mathrm{E}$, neste decenio subsequente, esta falta mais e mais se vem revelando.

Verificou-se que mistér se fazia facilitar o funcionamento da aeronáutica civil, esquecendo, por vezes, os textos porventura demasiadamente rígidos do Codigo do Ar.

Daí uma floração anômala de portarias, que não aplicavam o texto do Código: derrogavam-no, ao contrário, impedindo que o mesmo se estendesse aos vôos não comerciais.

Citaremos, entre elas:

a) A PORTARIA 194, de 1.\%/10/41, do Ministério da Aeronáutica, aprovando as instruções provisórias para a inspeção de saúde dos Pilotos de Turismo;

b) A PORTARIA 56, do Departamento de Aeronáutica Civil, dada aos 2/10/41, relativa ao registro dos "brevets" de piloto de aeronaves de recreio ou desporto.

Por outro lado, os rígidos textos do Código, explicaveis quando visavam a Companhias, explorando serviços regulares de navegação aérea, com fito de lucro, -- obrigavam a interpretações aberrantes das necessidades reais, quando urgia aplicá-los às aeronaves particulares, de simples turismo.

Veja-se, por exemplo, o douto parecer $n .^{\circ} 31$, da Consultoria Jurídica do Ministério da Aeronáutica, proferido nos Processos D.A.C. 469/41, 1.414/41 e 2.283/41. Parecer absolutamente coerente consigo mesmo, baseado com rigor nos textos legais. Envolvendo, porém, grave óbice para os pilotos particulares.

A conclusão é a seguinte: - aplica-se aos pilotos de turismo o art. 147 do Código do Ar. Logo,

“a carta de habilitação, e a respectiva licença de piloto de aeronave de turismo só podem ser concedidas a brasileiros..." 
E mais:

"mesmo aos titulares de "brevet" internacional, conferido pelo Aéro Club do Brasil, instituição filiada à Fédération Aéronautique Internationale, não se permitiu que tripulassem aeronaves nacionais..."

Tal interpretação levava a falhas importantes. Reconhece-o o parecer em apreço. Pois traria, entre outras conseqüências, facultar o Código ao brasileiro naturalizado matricular, no Brasil, aeronaves de sua propriedade, negando-lhe, porém, o direito de pilotá-las. Levava a considerar o piloto de turismo como "tripulante da aeronave", embora fosse proprietário dela, e a destinasse a passeios ou diversão.

Outras conseqüências ainda decorreriam infelizmente de tal interpretação: exames de saúde de dificil realização, somente perante médicos das Bases Aéreas; vistorias periódicas nas aeronaves, de obtenção dificil, dada a vastidão territorial do País e o pequeno número de técnicos, etc.

Urge, pois, criar, no Código do Ar reformado, o estatuto da aeronáutica civil. Principalmente visando:

a) Facilitar a aquisição de aeronaves de turismo;

b) Facilitar sua inscrição no Registro Aeronáutico;

c) Permitir o sobrevôo do País às aeronaves estrangeiras de turismo, que hajam sido registradas aqui, desde que seus pilotos estejam munidos de "brevets" do Aéro-Club do Brasil ou entidades filiadas, e o proprietário e o piloto não tenham sido processados por crime contra a Segurança Nacional e Ordem Política e Social (tomando-se por base as instruções baixadas a $24 / 2 / 47$ pelo Snr. Ministro da Aeronáutica) ;

d) Conceder facilidades para vistoria de aeronaves de turismo, e de exames médicos para seus pilotos;

e) Organizar uma nova modalidade de seguros aéreos compulsórios, cobrindo os terceiros, situados à superficie 
do solo, contra as conseqüências danosas dos acidentes, não só ocorridos com aeronaves comerciais, mas tambem com as de turismo e desporto.

\section{TAXIS-AÉREOS.}

O taxi-aéreo é uma modalidade de transporte aeronáutico, que necessita ser regulamentada.

Não está prevista pelo "Codigo do Ar", nem pela legislação anterior.

Esta, ao contrário, falava em "serviços regulares de navegação aérea", em "rótas prefixadas".

Entretanto, o taxi-aéreo triunfou. E, em 1947, foi baixada uma Portaria, autorizando seu funcionamento, exclusivamente, porém, em áreas não servidas pelas linhas regulares.

$O$ resultado desta restrição foi o desenvolvimento do transporte clandestino (principalmente nas zonas da Noroeste e da Alta Paulista). $\mathrm{E}$ isto, com todos os inconvenientes da clandestinidade: ausência de controle, falta de habilitação específica dos pilotos (munidos, exclusivamente, de "brevets" de turismo, etc.).

Buscando colher dados técnicos, que nos habilitassem a tentar solver este problema, procuramos o Snr. Hyra, piloto civil especializado, e submetemos a questão a debate, perante a União Brasileira de Aviadores Civis (U.B.A.C.).

$\mathrm{E}$, baseados nos resultados obtidos, propomos a inserção do seguinte

ARTIGO . - " $E$ ' licito a particulares a exploração do serviço de taxis-aéreos, mesmo em árias servidas pelas linhas regulares de navegação aérea, desde que o piloto possua "brevets" de piloto mercante, ou de instrutor, ou então haja sido aprovado em exame especial, prestado perante os orgãos competentes do Ministério da Aeronáutica.

$\S$ unico - Tais serviços, no entanto, só poderão ser explorados em vôo diurno, e por contato. 
A primeira exigência constitui uma tentativa de aumentar a segurança do transporte. $O$ piloto, munído de simples "brevet" de turismo, pode arriscar sua própria vida. Quando, se quizer dedicar a transporte de passageiros, mormente em árias mal servidas pela infra-estrutura, deve possuir prática maior, maior cópia de conhecimentos técnicos.

A concessão de "brevet", de piloto mercante ou de instrutor, estabelece uma presunção legal de competência. Caso não o possua, o candidato à pilotagem de taxis-aéreos deverá provar tal "virtuosidade" em exame especial.

O \& único explica-se, tambem:

1. ) dada a precariedade dos serviços de infra-estrutura nos aeródromos e campos de pouso, existentes no interior, - áreas em que o taxi-aéreo costuma desenvolver suas atividades;

$\left.2^{\circ}{ }^{\circ}\right)$ pelo fato de não estarem os taxis-aéreos sujeitos a horário, como as aeronaves comerciais.

o Snr. Hyra propôs-nos que incluíssemos um item, estabelecendo a obrigatoriedade das tarifas de tal modalidade de transporte serem superiores às cobradas pelos serviços regulares de aeronavegação.

Não nos parece, porém, que tal disposição, aliás justa, seja matéria incluivel em um Código. E' preferivel constitua ela objeto de um Regulamento ou Portaria.

Deixamos tambem de consignar a obrigatoriedade destes aviões transportarem aparelho de rádio emissão, dado o pequeno alcance dos serviços de rádio-escuta, existentes no interior.

\section{FOTOGRAFIAS AERONÁUTICAS.}

Sugerimos a inclusão do artigo seguinte:

ARTIGO ... - E' licito o transporte dos aparelhos fotográficos ou cinematográficos a bordo de 
aeronaves em vôo ou em pouso, bem como a fotografia ou filmagem de panoramas.

$\S 1 .^{\circ}$ - Excetuam-se, porém, os vôos realizados sobre áreas interditas à aéro-fotografia, a critério do Governo Federal.

$\S 2 .^{\circ}$ - Caso a aeronave tenha de sobrevoar, em seu percurso, tais áreas interditas à aéro-fotografia, todos os aparelhos fotográficos ou cinematográficos deverão ser lacrados, antes do aparelho levantar vôo do aeroporto ou aeródromo imediatamente anterior.

E' um sistema análogo ao instituido pelo Decreto 24.572, de 1934 .

A interdição generalizada de fotografia aérea, hoje constante do Regulamento do Tráfego Aéreo, somente se justifica em períodos de pré-guerra e não como princípio genérico, o que costuma levantar sempre dificuldades com os turistas estrangeiros.

\section{AUTENTICAÇÃo DAS FIRMAS, NAS FATURAS CONSUlaRES.}

Eis um dos mais árduos problemas que vêm dificultando a importação de aeronaves.

Entende a Diretoria de Aeronáutica Civil que a autenticação das firmas dos funcionários consulares somente pode ser feita pelo Ministério das Relações Exteriores.

Não há tal. Tanto a "Nova Consolidação das Leis, Decretos e Decisões referentes ao Corpo Consular Brasileiro", aprovadas pelo Decreto 10.384, de 6.8.1913, em seu art. 510; como o "Regulamento das Faturas Consulares", (Decreto 22.717, de 16.5.1933); e, ainda o Decreto 24.113, de 12.4.1934, que "aprova os regulamentos para os serviços diplomático e consular", seguem critério diverso.

Nada há que justifique tal função privativa, que se quer atribuir ao Ministério. 
Julgamos que a legalização aludida possa realizar-se, ou nos "Serviços Consulares" da Secretaria de Estado das Relações Exteriores (Decreto 19.926, de 28.4.31, art. 19, al. "g"), ou nas alfândegas e aeroportos aduaneiros, ou nas Procuradorias Fiscais da União. Ou, enfim, nas demais repartições aduaneiras, já existentes, ou que venham a ser criadas, em qualquer ponto do território nacional.

Embora essa matéria não tenha ligação direta com o Código do Ar, talvez pudesse nele ser incluido um artigo a respeito, para evitar as atuais interpretações restritivas.

A menos que se quizesse reviver a "CIRCULAR 23" de 5.6.35, do Ministério da Fazenda, que isentava da necessidade da autenticação as faturas consulares e comerciais, relativas à importação de aeronaves, ou de material conexo.

Com estas sugestões, estamos certos de que o tráfego aéreo alcançará maior desenvolvimento e eficiência. Libertar-se-á de certas peias excessivas, sem prejuizo para a segurança do País, dos aeronautas ou de terceiros, à superficie do solo. 